\title{
INGRESO Y CARRERA DOCENTE EN LAS UNIVERSIDADES PRIVADAS DE MENDOZA, ARGENTINA: \\ UNA PERSPECTIVA DESDE SUS ESTATUTOS E INFORMES DE EVALUACIÓN EXTERNA
}

\author{
Alejandra Lourdes Alaniz Bleisen ${ }^{1}$ \\ Docente adjunta en Facultad de Psicología de la Universidad del Aconcagua ${ }^{2}$ \\ Contactos: aalaniz@uda.edu.ar
}

\section{RESUMEN}

El objetivo de este trabajo es describir lo requisitos de ingreso para ser docente y el desarrollo de la carrera en sí dentro de las universidades privadas de Mendoza. Para su análisis se tomaron cinco universidades: Universidad de Mendoza; Universidad Maza; Universidad del Aconcagua; Universidad Champagnat; y la Universidad de Congreso.

Se presenta un recorrido bibliográfico enfocado en la gestión y desarrollo del recurso humano, a los fines de comprender el tema planteado. La descripción y análisis se realiza a partir de lo enunciado en los estatutos de las universidades privadas mencionadas y en los informes de evaluación externa de las mismas, publicados por la Comisión Nacional de Evaluación y Acreditación Universitaria (CONEAU).

Se presentó como limitación que solo se toma la perspectiva teórica y que hay una escasa publicación de trabajos científicos que muestren los procesos de ingreso y de carrera docente en las universidades privadas de Argentina.

Palabras claves: docencia; universidades privadas; estatutos; evaluaciones externas.

\section{ABSTRACT:}

The objective of this work is to describe the entry requirements to be a teacher and the development of the career itself within the private universities of Mendoza. Five universities were taken for analysis: University of Mendoza; Maza University; Aconcagua University; Champagnat University; and University of Congress.

A bibliographic tour is presented focused on the management and development of human resources, in order to understand the issue raised. The description and analysis is made from what is stated in the statutes of the mentioned private universities and in the external evaluation reports of the same, published by the National Commission for University Evaluation and Accreditation (CONEAU).

It was presented as a limitation that only the theoretical perspective is taken and that there is little publication of scientific works that show the processes of admission and teaching career in private universities in Argentina.

Key words: teaching; private universities; statutes; external evaluations

\footnotetext{
${ }^{1}$ Licenciada en Seguridad Ciudadana. Profesora de grado universitario. Doctoranda en Educación Superior por la Universidad de Palermo.

${ }^{2}$ Ubicada en Catamarca 361, M5500 GMH, Mendoza, Argentina. Sitio oficial:

https://www.uda.edu.ar/index.php/psicologia
} 


\section{INTRODUCCIÓN}

Con base en los aportes de Ganga Contreras, Abello Romero y Quiroz Castillo (2014:1120), se puede entender que, entre los alcances de la gobernanza universitaria, se encuentra el proceso de la toma de decisiones que involucra a distintos grupos de interés y que pueden analizarse de manera intraorganizacional, es decir, hacia adentro de la universidad. En este sentido puede examinarse el ingreso y la carrera docente en las universidades. Sin embargo, la carrera docente en las universidades privadas de Argentina ha sido poco estudiada, por lo tanto, no se cuenta con suficientes antecedentes al respecto. En el presente trabajo, se describen los hallazgos en relación a la carrera docente de cinco universidades privadas de la provincia de Mendoza, Argentina.

Con el propósito de contextualizar al lector, se brinda una breve reseña sobre la creación de estas universidades. También se incluye un análisis teórico de bibliografía, con el que se busca comprender la función del docente universitario y sus características.

Luego se describen los enunciados relacionados al ingreso y a la carrera docente, provenientes de los estatutos y reglamentos de las universidades analizadas. Se incluye un apartado para describir los resultados vinculados a la carrera docente que ha publicado CONEAU en los informes finales de evaluación externa de las universidades privadas analizadas.

Finalmente, se incorpora una conclusión y sugerencias de mejora para el ingreso y desarrollo de la carrera docente en las universidades privadas mendocinas.

\section{MATERIAL Y MÉTODOS}

Se ha optado por un diseño descriptivo centrado en un análisis documental y bibliográfico respecto al ingreso y desarrollo de la carrera docente en universidades privadas en Mendoza.

Se presenta aquí una limitación de praxis, dado que se trata de un artículo centrado en la perspectiva teórica, en la revisión bibliográfica, de documentos normativos y de datos extraídos de fuentes secundarias.

\section{PROCEDIMIENTO}

El trabajo se inicia con una introducción. Luego se profundiza en la creación de estas universidades privadas. Se continúa con una revisión de literatura en torno al significado, funciones de la docencia y al desarrollo de la carrera docente en universidades argentinas.

Finalmente, se describen todos los hallazgos encontrados en estatutos y reglamentos, así como en informes finales de evaluaciones externas realizadas por CONEAU, que brindan 
algunos datos extras sobre el ingreso a la docencia y la carrera docente en las Universidades Maza, de Congreso, de Mendoza, Champagnat y del Aconcagua. El trabajo está construido en su totalidad, por el aporte de fuentes secundarias.

\section{CREACIÓN DE LAS UNIVERSIDADES PRIVADAS}

Recién a partir del año 1958 el Estado argentino permite la creación de universidades de gestión privada. Sin embargo, para lograr este permiso, las universidades privadas recorrieron un extenso camino hasta ser reconocidas como tales. Muchas personalidades influyeron el debate ante la necesidad de creación de "universidades libres, privadas, no oficiales" que se encargaran de la investigación para sectores empresariales e industriales. Entre estas personas, pueden mencionarse a Enrique Gaviola y Eduardo Braun Menéndez, quienes fueron impulsores en las propuestas de creación de universidades privadas (Del Bello, Barsky \& Giménez, 2007:61-74).

En 1941 Joaquín V. González iniciaba un debate en torno a que se necesitaba una nueva universidad, que otorgara títulos de valor académico. En 1946, con otro proyecto de ley propulsado por la Unión Cívica Radical, se proponía autorizar la creación de universidades libres bajo dos condiciones. Una, que fueran controladas por un Consejo Universitario Nacional y otra, que no recibieran subsidios del Estado. Este año el proyecto tampoco prosperó, dado que de manera similar a 1943, donde las universidades fueron intervenidas nuevamente (Del Bello et al., 2007: 68-69).

En 1947 el justicialismo llevó al Congreso y logró la aprobación de la ley número 13031, que modificaba la "Ley Avellaneda" (número 1597/1885). Esta ley mantenía la facultad del otorgamiento de títulos habilitantes exclusivamente para las universidades estatales, pero generaba un cuerpo docente dedicado exclusivamente a la investigación y docencia. En estos años la iglesia aunaba esfuerzos para lograr fundar una Universidad Católica (Del Bello et al., 2007: 73). Algunos hechos marcaron los acontecimientos previos a la creación de universidades privadas. En 1949 el peronismo eliminó los aranceles de las universidades estatales por medio del Decreto número 29337 emitido el 22 de noviembre de ese año (Rosenberg, 2016). En este mismo año, recién se incorporó en la Constitución Nacional el concepto de "autonomía universitaria" (Del Bello et al., 2007: 70). A partir de 1952 se comenzó a difundir de manera obligatoria la obra y doctrina peronista en los ámbitos educativos. Al año siguiente, se eliminó el examen de ingreso (Del Bello et al., 2007: 70-74).

En 1955 una nueva intervención militar encabezada por Lonardi y Aramburu, le quitó el poder a Perón. La intervención militar duró dos años, entre las acciones que implementaron se encontró la de reinstalar la "Ley Avellaneda" aunque por poco tiempo ya que se sancionó el Decreto-Ley 6403 que incorporaba ingreso a las universidades por concurso y traspasaba la designación de autoridades (antes a cargo del Poder Ejecutivo Nacional -PEN) a la misma universidad. Además, en su Artículo 28 permitía la creación de universidades libres que deberían someterse a lo que estableciera la reglamentación. 
El mencionado artículo $28^{\circ}$, parecería un avance, pero se transformó en otro de los tantos intentos fallidos ya que la reglamentación no se logró hasta 1958. Es este año, el presidente electo Arturo Frondizi impulsó la reglamentación de este artículo. El impulso se transparentó por medio de la Ley número 14557, conocida como "Ley Domingorena", que brindaba la atribución de expedir títulos y diplomas académicos a las universidades privadas. Esta ley fue reglamentada por el Decreto 1404 en 1959, donde se establecía que las universidades privadas debían tener personería jurídica y no permitía que recibieran financiamiento estatal (Del Bello et al., 2007: 82-84).

Con la "Ley Domingorena" comenzaron a fundarse varias universidades de gestión privada. Es en este contexto que se fundan las universidades privadas en Mendoza. La actual ley de educación superior argentina, número 24.521/95 establece entre los artículos $62^{\circ}$ y $68^{\circ}$, las condiciones para la creación de una universidad privada. En los siguientes apartados se enuncian brevemente algunos aspectos sobre la creación de las universidades privadas de Mendoza que se incluyen en este trabajo.

\section{UNIVERSIDAD MAZA}

La Universidad Maza fue creada en 1963 (CONEAU, 2017: 40). Aunque su inicio se registró el 4 de mayo de 1960, con dos facultades (Del Bello y otros, 2007: 129). Según la página institucional de esta universidad, fue la primera universidad privada en obtener el reconocimiento como tal dentro de la provincia, y la novena a nivel nacional (Universidad Maza, s.f.).

\section{UNIVERSIDAD DE MENDOZA}

La Universidad de Mendoza fue creada en 1962 (CONEAU, 2017: 40), año en el que obtuvo su reconocimiento oficial. La misma fue fundada por un exdiputado y exdirector General de Escuelas de la provincia, el Dr. Emilio Descotte. Él dio inicio a la Facultad de Ciencias Jurídicas y Sociales, el 6 de mayo de 1960 (Del Bello y otros, 2007: 128-129).

\section{UNIVERSIDAD DEL ACONCAGUA}

Los orígenes de la Universidad del Aconcagua (UDA) se remontan a reuniones de un grupo de amigos que debatían sobre las realidades que atravesaba el país en los '60. Este grupo, según el libro Universidad del Aconcagua 50 años estaba conformado por dieciséis personas (UDA, 2018: 15). Entre los debates de este grupo surgió con fuerza una idea: "nuestra región necesitaba profesionales debidamente preparados frente a esos cambios. El mundo empresario reclamaba Una institución que propiciara dicha formación” (UDA, 2018: 23). 
La actual UDA dio sus primeros pasos en 1965 creando el Instituto Superior de la Empresa, en 1966 el Instituto de Psicología y en 1967 comenzaron a incorporar más carreras. El primer ciclo comenzó en 1967 (Del Bello y otros, 2007: 131). La Universidad el Aconcagua obtuvo una autorización provisoria por medio del Decreto del PEN número 2227, emitido el 29 de abril de 1968.

Según el informe de evaluación externa (CONEAU, 2018: 18) la UDA obtuvo el reconocimiento definitivo para funcionar como universidad por medio del Decreto 4111 de 1973.

\section{UNIVERSIDAD CHAMPAGNAT}

La Universidad Champagnat fue creada en 1991 (CONEAU, 2017:40), aunque sus orígenes se remontan a 1967, con la fundación del Instituto Superior Champagnat a cargo de los Hermanos Maristas. Cuatro años más tarde, pasaron a formar parte de la Universidad Católica de Cuyo de San Juan (Del Bello y otros, 2007: 140).

Con el paso del tiempo, los miembros deciden separarse de la Universidad Católica de Cuyo dada la dificultad del control de la gestión académica. Por tal motivo, en 1991 se otorga autorización provisoria, mientras que en 1994, el Ministerio de Educación le otorga el reconocimiento definitivo. En 1999 fallece su fundador, quien, por lo normado en el estatuto, era el único que podía designar a los miembros del Consejo. Este hecho generó varias intervenciones a nivel nacional y provincial. Recién en el 2012 su funcionamiento se normaliza y en el 2013 el Ministerio de Educación aprueba un nuevo estatuto de la Universidad (CONEAU, 2016-a:1318).

\section{UNIVERSIDAD DE CONGRESO}

La Universidad de Congreso fue creada en 1994 (CONEAU, 2017: 41), donde obtuvo una autorización provisoria para funcionar con tres carreras, administración, comercialización y relaciones internacionales (Del Bello y otros, 2007: 145). En 1995 se aprobó su estatuto y comenzó a funcionar, pero ese mismo año matricularon a alumnos en carreras que no habían sido autorizadas, ya que no aparecían en el proyecto institucional presentado ante el Ministerio de Educación. Por varios años continuó funcionando de esta manera, aunque todas las carreras obtuvieron habilitación por Resolución del Ministerio de Educación, que permitía que las mismas se agregaran al plan institucional (CONEAU, 2011: 9-11). Recién en el año 2014 obtuvo su reconocimiento definitivo (Universidad de Congreso, s.f.).

\section{EL INGRESO A LA DOCENCIA UNIVERSITARIA}


Según lo establecido en la ley de educación superior argentina, número 24.521 (1995), las universidades tienen la atribución de "Establecer el régimen de acceso, permanencia y promoción del personal docente y no docente" (art. 29º inc. h). Como requisito, la legislación establece que "los docentes deben poseer título de igual o superior nivel a aquel en el cual ejercen la docencia" (art. 36 $)$. Pero, ¿qué significa ser docente? Para comprenderlo, se toman algunos autores que brindan un acercamiento al respecto.

Marquina (2013) afirma que la docencia es una profesión que no puede pensarse como actividad independiente, ya que es necesario que se enmarque en una institución. Ella sostiene que la actividad académica se caracteriza por ciertas reglas de ingreso y permanencia, entre ellas, los concursos, a los que entiende como la forma "más tradicional". Otra de las características que menciona, es que, en Argentina, la profesión académica se desarrolla principalmente con dedicación a tiempo parcial, como una profesión de periferia, sobre todo en las carreras profesionalistas.

Sarramona, Noguera y Vera (1998) sostienen que la profesión docente está caracterizada por una gran heterogeneidad. Sus alcances pueden depender de las funciones que se desarrollen, por ejemplo, estar frente a un aula, ser un docente de apoyo, o formar parte de la conducción. Otra de las características surge en virtud de su situación de revista. Entre las categorías, puede ubicarse a los docentes titulares ordinarios, a los suplentes o contratados, y a su vez, a los interinos. Sus características también dependerán de su formación, si es solo disciplinar o si cuenta con un conocimiento pedagógico especializado. Otra característica que se menciona, es la del compromiso de actualización o del nivel en el que se desempeñe, aclarando que se aprecia una percepción de prestigio en la docencia universitaria. También se menciona el compromiso deontológico al que el docente adhiere por tradición, sin necesidad de que el mismo se encuentre escrito (uso y costumbre).

\section{EL DESARROLLO DE LA CARRERA DOCENTE EN UNIVERSIDADES ARGENTINAS}

En las universidades públicas, el ingreso a la carrera docente, se debe realizar mediante concurso, aunque hay excepciones (Congreso de la Nación Argentina: Ley 24521, 1995, art. $51^{\circ}$ ). Mientras que la carrera docente puede ser definida en virtud de la autonomía universitaria, mayormente está ligada a las vacantes, al desempeño de actividades de investigación y en ocasiones, también a la evaluación de desempeño. Algunos autores (Sarramona y otros, 1998), vinculan la promoción docente con el perfeccionamiento constante.

Los sistemas académicos se encuentran divididos por sectores y jerarquías (Clark, 1983). Las universidades privadas no responden a un sistema puro de división, ya que, si bien el financiamiento es privado, las regulaciones provienen del sector público, es decir, que existe una interdependencia. Esto es enunciado por Clark como la cuarta modalidad de distribución, en la 
que intervienen sectores múltiples (1983: 22). En el siguiente apartado se reseña la historia de las universidades privadas.

\section{ESTATUTOS SOBRE LA DOCENCIA EN LAS UNIVERSIDADES PRIVADAS DE MENDOZA}

La ley argentina de educación superior, en su artículo $29^{\circ}$, inciso a, establece que las universidades tienen la atribución de dictar y reformar sus estatutos. Cuando las universidades sancionan su estatuto, deben enviarlo al Ministerio de Educación a los fines de que este indique si se adecúa a la normativa vigente o si debe modificarse. El Ministerio dispone de diez días para solicitar modificaciones del estatuto, en caso de que no lo haga, se entiende que el mismo ha sido aprobado. Los estatutos entran en vigencia a partir de su publicación en el Boletín Oficial de la República Argentina (Ley 24521, 1995, artículo 34º).

Entre los aspectos que deben consignarse en un estatuto, se encuentra el régimen de la docencia y de la investigación. Clark (1983: 28) indica que la división del trabajo se caracteriza cada vez más por la fragmentación en el interior de las universidades. Esa fragmentación interior puede apreciarse al ver la estructura de los estatutos o reglamentos. Se describe en los apartados posteriores, lo enunciado al respecto en los estatutos o reglamentos de las universidades privadas mencionadas precedentemente.

\section{UNIVERSIDAD MAZA}

Del artículo $46^{\circ}$ al $62^{\circ}$ del estatuto de la Universidad Maza, se establece todo lo relativo al personal docente y de investigación. Entre las condiciones para ser docente universitario menciona que es necesario contar con un título igual o superior al nivel al que aspira ejercer la docencia; estar comprometido con los objetivos de la universidad; perfeccionarse y actualizarse constantemente.

También se enuncian todas las obligaciones del personal docente y sus derechos. Mencionan lo que comprende la libertad académica y determinan algunas limitaciones sobre la misma.

La categorización docente establece por un lado a los profesores y por otro, a los auxiliares de docencia. Clasifica a los profesores como ordinarios, que pueden tener la subcategoría de titulares, asociados o adjuntos; extraordinarios, que pueden tener la subcategoría de emérito, honorario, consulto o invitado; interinos; contratados y suplentes. En cuanto a los auxiliares docentes, establece las subcategorías de jefe de trabajos prácticos, ayudantes diplomados o ayudantes alumnos.

La designación de los docentes se realiza por medio del rector, a pedido de los decanos. Pueden ser incorporados mediante nombramiento o por medio de un contrato especial. 


\section{UNIVERSIDAD DE MENDOZA}

En la página de la Universidad de Mendoza se indica que las últimas modificaciones parciales del estatuto fueron realizadas el 31 de agosto de 1994 . Entre los artículos $42^{\circ}$ y $58^{\circ}$, se enuncia todo lo relativo al cuerpo docente. Sobre los mismos establece las categorías de profesores titulares, profesores asociados y profesores adjuntos, que pueden ser ordinarios o interinos. También las categorías de profesores extraordinarios, contratados y suplentes, que pueden ser titulares o adjuntos. Finalmente incorpora la categoría de auxiliares docentes, que pueden ser jefes de trabajos prácticos, ayudantes de cátedra diplomados, ayudantes de trabajos prácticos diplomados, o ayudantes alumnos.

El claustro de profesores de la universidad solo está conformado por los profesores ordinarios titulares, asociados o adjuntos y son los únicos que tienen sufragio activo y pasivo; de manera similar a lo que ocurre en las universidades públicas.

Los profesores de esta universidad pueden desempeñarse como máximo en dos cátedras por facultad. En cuanto a los requisitos para ser docente titular o asociado, se indica que deben contar con diez años de antigüedad en el ejercicio de la profesión y 6 en el ejercicio de la docencia universitaria. Mientras que para ser docente adjunto se requieren seis años de ejercicio en la profesión y tres en docencia universitaria. Esta tendencia a priorizar el ejercicio profesional es coincidente con una de las tendencias que complejizan la profesión académica en las universidades nacionales (García de Fanelli, 2008).

El estatuto, menciona que para todas las designaciones se considerará la probidad moral y el decoro público; la antigüedad en la docencia universitaria; los trabajos de investigación realizados y los títulos o cargos públicos ocupados. La primera designación de los profesores, será de forma interina y por un año, aunque pueden prorrogarlo por dos años más. Mientras que la designación de los docentes auxiliares, solo serán anuales e interinas. Todas las designaciones de los docentes caducarán automáticamente a los 70 años de edad. También se enuncian las obligaciones del personal docente y las categorías de los investigadores.

\section{UNIVERSIDAD DEL ACONCAGUA}

En el reglamento de la Universidad del Aconcagua (UDA), se establecen aspectos sobre el personal docente entre sus artículos $124^{\circ}$ y $171^{\circ}$. En este reglamento, lo primero que se consigna es que todos los docentes realizarán tareas de investigación y que los investigadores, tendrán tareas docentes. Se menciona que las designaciones docentes podrán ser interinas o efectivas. Las interinas no tendrán un término mayor de un año y podrán ser renovadas. Mientras que las efectivas, serán por concurso y durarán 5 años.

Se establecen algunos requisitos para los distintos cargos. Para ocupar el cargo de profesor titular efectivo se debe contar con cinco años de experiencia en condición de profesor titular contratado o interino: contar con algún curso de planificación docente; tener publicaciones o 
haber actuado como disertante fuera de la provincia y dictar una clase sobre un tema que se le dará a conocer con 24 horas de anticipación, en el que se valorará las condiciones pedagógicas frente al alumnado. El profesor titular efectivo puede ser confirmado definitivamente en su cargo. Sobre la evaluación de la clase, menciona que se realizará por un tribunal integrado por tres profesores titulares.

El estatuto establece clasificaciones para los docentes en virtud de su carácter, de su condición, de su dedicación y de su función. En virtud de su carácter pueden ser profesores ordinarios, entre los que se encuentran titulares, asociados, adjuntos y consultos; profesores extraordinarios, entre los que se encuentran eméritos, visitantes y honorarios; docentes medios, entre los que se encuentran jefes de trabajos prácticos y auxiliares de la docencia; y docentes autorizados.

Con base en su condición, pueden ser profesores efectivos, contratados e interinos. Mientras que, por su dedicación pueden ser de dedicación exclusiva o de tiempo completo, de dedicación semiexclusiva o de tiempo parcial y con dedicación simple. En razón de su función pueden ser responsables de cátedra, curso o equivalente; tutores; especialistas externos; docentes de apoyo; coordinadores de actividades externas o internas; y supervisores. En el estatuto se establecen las funciones para cada una de estas categorías y que los profesores pueden ser relevados de sus funciones luego de cumplir 65 años de edad.

En cuanto a la carrera docente establecen que, para ser designado como profesor o investigador, no es necesario contar con antecedentes en carreras de docencia o de investigación $\left(\operatorname{art} .157^{\circ}\right.$ ). También se establece que los docentes e investigadores pueden ser sometidos a juicio académico.

Incorpora también la categoría de las adscripciones para los egresados universitarios o quienes adeudan hasta dos materias para recibirse. Los que cumplan este requisito pueden adscribirse a una cátedra durante dos años. También se incorpora la categoría de los ayudantes de cátedra o monitores, que pueden ser ocupadas por estudiantes que hayan aprobado el tercer año completo de la carrera que cursen. Esta designación será solo por un año y con opción a otro.

\section{UNIVERSIDAD CHAMPAGNAT}

El estatuto de la Universidad Champagnat (2013) establece aspectos vinculados a los docentes e investigadores en los artículos $21^{\circ}, 22^{\circ}$ y $23^{\circ}$. Entre las condiciones para la designación establecen que debe poseer un título universitario igual o superior al que aspira para ejercer la docencia.

Para la carrera docente se establece que el claustro docente tendrá las categorizaciones de profesores extraordinarios, la que tendrá como subcategoría a docentes eméritos, honorarios, docentes visitantes y a docentes consultos. La otra categoría será la de profesores ordinarios que incluye como subcategorías a los docentes adjuntos, a los asociados y a los titulares. Para cada uno de ellos establece determinados requisitos. 
Para ser docente adjunto se deberá contar con título de grado y acreditar tres años de docencia en el nivel superior, poseer antecedentes investigación y se tendrá en cuenta la formación pedagógica didáctica. Mientras que para ser docente asociado, se requerirá poseer título de grado, acreditar cuatro años de docencia en el nivel superior y dos de ellos en el nivel universitario, acreditar antecedentes académicos o profesionales en los últimos dos años, haber realizado publicaciones en los últimos cinco años. Para las cátedras de formación profesional, además, se deberá contar con antecedentes en el desempeño profesional y se valorará la formación pedagógica didáctica.

Para ser docente titular, acreditar cinco años en el nivel superior y tres en el universitario, haber publicado en los últimos años, para las cátedras de formación profesional se exigirán antecedentes en el desempeño de la profesión, haber realizado actividades de extensión o transferencia en los últimos cinco años y poseer título de posgrado. Para la categoría de docencia que incluye a los jefes de trabajos prácticos y a los ayudantes de cátedra los requisitos se flexibilizan.

\section{UNIVERSIDAD DE CONGRESO}

El estatuto estipula que, para acceder a cualquier categoría docente dentro de la universidad, se debe contar con título universitario igual o superior al que se aspira ejercer en la docencia. Indica en la categorización docente a los profesores ordinarios, entre los que se encuentran los docentes adjuntos, los asociados y los titulares. También categoriza a los auxiliares de la docencia, entre los que se encuentran los jefes de trabajos prácticos y los ayudantes de laboratorio o de cátedra. La tercera categoría que establece es la de profesores extraordinarios, entre los que se encuentran los docentes eméritos, los visitantes y los consultos.

El artículo 43 del estatuto establece que los docentes deberán ser propuestos por cada decano o director de departamento al vicerrector académico, y serán designados con anuencia del rector. También se mencionan los derechos y las obligaciones del personal docente, así como las categorizaciones de los investigadores.

Esta universidad cuenta además con un reglamento interno (2019) que amplía lo enunciado en el estatuto. En este reglamento agrega dentro de la categoría de docente extraordinario, al doctor honoris causa. También establece la categoría de docente adscripto ad honorem, a la que solo pueden acceder las personas que tengan título universitario de grado. La adscripción dura un año y puede ser renovada. En cuanto a la categoría de ayudante alumnos ad honorem, establece que podrán acceder a la misma, los estudiantes que tengan aprobado como mínimo el 50\% de las asignaturas de su carrera y quién no cuente con sanciones disciplinarias.

La carrera docente ha sido reglamentada mediante el Anexo 01 de la Resolución 04 del año 2014. En este se establece que el ingreso a la carrera docente, debe realizarse mediante concurso público de antecedentes con oposición o a través de trámite abreviado. 
Se establecen las funciones para cada una de las categorías docentes y también sus requisitos, los que van aumentando junto con la categorización. Para ser profesor adjunto, se debe contar con experiencia pedagógica didáctica de 120 horas reloj como mínimo y con publicaciones o antecedentes en investigación en los últimos cinco años. Para ser docente asociado se requiere contar con cinco años de experiencia en el nivel superior y tres de ellos el nivel universitario, acreditar también formación pedagógica didáctica como mínimo de 240 horas y haber realizado actividades de extensión en los últimos cinco años.

Para acceder a la categoría de docente titular, se exige contar con título de posgrado, preferentemente de doctorado, acreditar ocho años de experiencia docente en el nivel superior y cinco de ellos en el universitario, acreditar formación pedagógica didáctica como mínimo de 360 horas reloj, contar con una publicación en revista con referato en los últimos cinco años y tener antecedentes de investigación. Como excepción establece que el Consejo Académico Universitario puede designar docentes que no tengan estos requisitos, pero que cuente con otros méritos intelectuales y morales.

Este reglamento detalla las funciones de los docentes extraordinarios y también el procedimiento para ingresar por medio de concurso público de antecedentes. Sobre este punto brindan todos los aspectos relativos a la convocatoria, difusión, el proceso de inscripción, la función de la Comisión Asesora Universitaria, la forma en que se analizarán los antecedentes, cómo será el dictamen y en qué consistirá la clase pública o el coloquio que deban realizar los aspirantes. Incluso han dejado establecido el modelo del currículum que se debe presentar en los llamados, así como la grilla de evaluación y los puntajes máximos a asignar.

También mencionan que la promoción de categoría, puede realizarse mediante trámite abreviado cuando surja una vacancia y los directores de los departamentos lo propongan.

\section{INFORMES FINALES DE EVALUACIÓN EXTERNA EN LAS UNIVERSIDADES PRIVADAS DE MENDOZA}

Estos informes responden a una evaluación institucional, que para las universidades argentinas está contemplada en el artículo $44^{\circ}$ de la ley de educación superior 24.521 (Congreso de la Nación Argentina: Ley 24521, 1995, art. 51º). CONEAU (2016-b: 11), indica que la misma "comprende dos instancias: la autoevaluación institucional a cargo de la institución universitaria, y la evaluación externa a cargo de CONEAU'. En primera instancia, la propia comunidad educativa de la institución se evalúa así misma; y luego lo hace un comité de pares evaluadores que envía CONEAU. Los resultados son publicados en un informe final de evaluación externa. Se presenta a continuación un análisis de aspectos vinculados a los docentes, que se enuncian en los informes de evaluación de las universidades privadas seleccionadas.

\section{UNIVERSIDAD MAZA}


El informe final de evaluación externa realizado por CONEAU en la universidad Maza (2018) indica que la misma cuenta con 985 docentes, de los cuales, 673 son profesores y los restantes, auxiliares. De los 985 docentes, solo 54 tienen dedicación exclusiva, mientras que más del 60\% tiene dedicación simple o menor (CONEAU, 2018: 67). En este informe se indica que la dimensión del cuerpo docente es excesivamente alto, comparado al número de alumnos (4795). El 28\% de los docentes, tiene formación de posgrado, lo que para CONEAU es un porcentaje bajo (CONEAU, 2018: 68).

En cuanto al ingreso de nuevos docentes, han establecido un procedimiento de concurso de antecedentes, mecanismo que se realiza por convocatoria pública, y luego hay una entrevista que es realizada por el director de carrera, el decano y la vicerrectora académica. La primera designación dura solo un año, la cual puede prorrogarse por un año más o puede ser nombrado como profesor interino. Para pasar de profesor interino a profesor ordinario, es necesario contar con diez años en el carácter de profesor interino y poseer título de posgrado.

En cuanto a la promoción en la carrera docente, establecen que primero es necesario que surja una vacante, para abrir un proceso de selección liderado por personal propio de la universidad. Sobre esto último CONEAU indica "que no contribuye a promover la calidad de los procesos de selección y evaluación del plantel docente” (CONEAU, 2018: 70).

Entre las recomendaciones de CONEAU, se encuentra la de designar a los docentes en función de la dedicación y no por horas. También la de mejorar el procedimiento de selección y criterio de promoción, incluyendo para el mismo la participación de otras instituciones la evaluación de este proceso.

\section{UNIVERSIDAD DE MENDOZA}

El último informe de evaluación externa en la Universidad de Mendoza, que ha sido publicado por CONEAU, corresponde al año 2000. Sin embargo, las noticias indican que la universidad de Mendoza fue sometida a una nueva evaluación de CONEAU en el año 2012, pero sus resultados no se hallaron publicados. A los fines de contextualizar la universidad, se toma un documento que puede entenderse como desactualizado, ya que considera aspectos de la universidad desde hace más de 20 años.

En 1999 la universidad analizada, contaba con 532 docentes, distribuidos entre las categorías de profesor titular, asociado y auxiliar de docencia. Además, con distintas dedicaciones, extraordinarias, intermedias y simples. Aunque gran parte de la función docente se cumplía con dedicaciones simples. Mientras que la dedicación extraordinaria era prácticamente inexistente.

En cuanto al ingreso y promoción de la carrera docente, este informe indica lo mismo que se encuentra consignado en el estatuto. Para ser profesor titular o adjunto se requiere contar con una antigüedad mínima en el ejercicio de la docencia, aunque para ser titular se requieren más años que para ser adjunto. Entre otros requisitos que enuncian, se encuentran los de la probidad 
moral y el decoro público, antecedentes en investigaciones, participación en congresos y ejercicio de cargos públicos. El informe de CONEAU entiende que estos criterios de selección están influenciados por la facultad de derecho, pionera de esta universidad.

Solo los profesores titulares asociados o adjuntos pueden ser designados como profesores ordinarios y pasar a integrar el claustro docente. Mientras que el profesor interino es el que no alcanza aún la confirmación definitiva y su designación es renovable.

CONEAU indica que en la práctica tanto el ingreso como la promoción de los docentes, no es muy clara ya que hay criterios informales y subjetivos. También mencionan que hay una tendencia a prever el ingreso de nuevos docentes por medio de la categoría de ayudante alumno y de adscripto, ambos con carácter ad honorem. Estas dos categorías son entendidas como semilleros para la incorporación de nuevos docentes.

$\mathrm{El}$ informe de CONEAU detectó una tendencia a incorporar exalumnos al plantel docente, es decir a los mismos egresados de la Universidad de Mendoza. También se detectó que la universidad de Mendoza no contaba en ese momento con cursos de formación continua, actualización o perfeccionamiento para sus docentes. Tampoco, con un mecanismo claro de evaluación del desempeño docente y de seguimiento de actividades académicas.

En las recomendaciones, se sugiere fortalecer el desarrollo de un perfil académico que tenga en cuenta la formación pedagógica y científica. También mejorar la reglamentación de adscriptos y ayudantes de cátedra e incentivar el desarrollo de actividades de investigación y modificar el estatuto para priorizar criterios académicos, y no solo la antigüedad profesional.

\section{UNIVERSIDAD DEL ACONCAGUA}

En el informe final de evaluación externa (CONEAU, 2017: 71) se menciona la normativa de la Universidad del Aconcagua referida al plantel docente. Reseñan que las dedicaciones en esta universidad pueden ser exclusivas o de tiempo completo (40 horas semanales), semiexclusivas o de tiempo parcial (25 horas semanales) y simples (10 horas semanales).

El docente designado con mayor dedicación, tiene una carga horaria con al menos tres días por semana de asistencia a la unidad académica en la que se desempeña. Aquí se mencionan también las incompatibilidades, para los funcionarios que no están enmarcados en un convenio de trabajo, tales como decanos, secretarios académicos y directores de carrera; quienes solo pueden tener dos cargos docentes con dedicación simple y dictar hasta dos cursos por año. Se establece como limitación que se podrá cubrir hasta un 5\% de los cargos docentes de cada unidad académica, con dedicaciones exclusivas.

En este informe se menciona que el porcentaje de docentes con dedicación exclusiva es escaso y que hay una tendencia a los cargos de profesores titulares seguidos por jefes de trabajos prácticos, con una baja representación de profesores asociados y adjuntos; lo que debería reverse para planificar el retiro de los profesores titulares que se encuentran cerca de la jubilación (CONEAU, 2017: 76). 
También se indica que, cuenta con 1809 docentes y solo el 3,8\%, posee título de doctor ( 70 docentes). Se menciona que los docentes pueden tener distintos cargos según se trate por su carácter, su condición, su dedicación o su función.

En relación al ingreso a la docencia, se menciona que se realiza por medio de la selección de antecedentes. Se destaca la formación docente continua que se ofrece tanto desde rectorado, con una especialización en gestión de la educación superior, como desde la Facultad de Psicología, con una diplomatura en docencia universitaria. Aunque se sugiere que estas propuestas pueden ser ofrecidas a otras facultades o escuelas, como oportunidad formativa y de integridad institucional (CONEAU, 2017: 81).

Finalmente, en las recomendaciones que realiza no se menciona ningún aspecto con la carrera docente, solo que debe implementar un sistema de evaluación docente.

\section{UNIVERSIDAD CHAMPAGNAT}

Según el informe final de evaluación externa publicado por CONEAU (2016-a: 71-78), la Universidad cuenta con 547 docentes, que tienen entre 25 y 45 años. La mayoría de los docentes solo ha alcanzado una titulación de grado. De hecho, solo el 5\%, es decir, 30 docentes han alcanzado el nivel de doctorado.

En cuanto a la dedicación, más del $60 \%$ trabaja 9 horas cátedra o menos, lo que denominan de dedicación menor y solo el 3\%, es decir, 16 docentes, trabajan semanalmente 30 horas cátedras o más, lo que puede entenderse como dedicación exclusiva o mayor. Solo el $9 \%$ del plantel docente tiene antecedentes de formación en docencia universitaria.

El informe no menciona nada sobre ingreso o promoción de la carrera docente, solo la necesidad de implementar capacitación y formación que no sea arancelada.

En cuanto a las recomendaciones que realiza CONEAU, se encuentra la de reacomodar la planta e implementar la carrera docente como mecanismo para el ingreso y la promoción de docentes. Esta recomendación la sustentan en que la estructura de los cargos docentes deja en evidencia un desequilibrio y una distribución desigual en torno a las dedicaciones (CONEAU, 2016-a: 104-106).

\section{UNIVERSIDAD DE CONGRESO}

En el informe de evaluación externa de la Universidad de Congreso, publicado por CONEAU (2011), reseña que la normativa del Universidad de Congreso establece distintas categorías docentes. Dentro de la categoría de docentes ordinarios, se encuentran los profesores titulares, asociados, adjuntos, jefes de trabajos prácticos y ayudantes de trabajos prácticos. Mientras que, en la categoría de profesores extraordinarios, se encuentran los eméritos, honorarios, consultos y visitantes. 
Algunos puntos indicados como "debilidades" en este informe y que ya han sido subsanados por normativa institucional más reciente, no se profundizará. Sin embargo, se aclara que tiene que ver con la cantidad de horas exigidas al personal en relación a lo pedagógicodidáctico; al plan para formar a los docentes; a la reglamentación para la promoción y dedicación; respecto de la evaluación selectiva y el procedimiento para el llamado externo; la grilla de evaluación con los puntajes máximos que se podrían asignar, régimen de carrera docente y de selección del personal académico mediante concursos públicos de antecedentes; el trámite abreviado de nombramiento.

La planta docente de la Universidad de Congreso en el 2007, era de 424 docentes, constituida mayormente por jóvenes. En el 2007 solo el 6\% de los docentes contaba con título de profesor. Este informe sostiene que la mayoría de los profesores fueron contratados mediante un sistema de horas cátedra, que no contempla las otras actividades inherentes a la docencia como la planificación, la elaboración del material y la evaluación, es decir que no hay una renta específica por estas actividades.

Entre las recomendaciones, CONEAU sugiere incorporar una evaluación de desempeño docente que no esté limitada solo a la opinión de los alumnos. Además, reformular la estructura de dedicación de los docentes, persiguiendo como horizonte un sistema de mayor dedicación. Trabajar en un plan de formación para la actualización de los recursos humanos docentes y reducir los aranceles de los posgrados para los docentes propios de la universidad, e incluso brindar gratuitamente los cursos de formación docente (CONEAU, 2011: 119).

\section{CONCLUSIONES}

Altbach (2009) sostiene que lo más importante en una universidad son los docentes y que los problemas más graves que se enfrentan, tienen que ver con que faltan docentes con doctorados, también con formación pedagógica, y que cada vez, aumentan más los docentes con baja dedicación, entre otros aspectos. Este enunciado de Altbach resume claramente algunas de las dificultades enunciadas en los informes de CONEAU. Dificultades que dejan en evidencia que no hay políticas claras en las universidades privadas de Mendoza que garanticen la carrera docente.

En relación a las formas de promoción en la carrera docente, Doberti (2017) sostiene que distinguir a los docentes según sus categorías, es muy importante para analizar la estructura organizacional. En similar sentido, la importancia de que las normas sean claras para el ingreso, promoción y régimen de dedicaciones. Esto último ha sido reiterado en los informes de CONEAU cuando muestra las debilidades de las universidades privadas de Mendoza.

Aunque la normativa de las universidad de Congreso, Maza y Aconcagua establezcan el ingreso mediante concurso, CONEAU ha indicado que en la práctica no queden claros los procesos para acceder a la carrera docente por medio de concursos, Esto puede explicarse a partir de lo enunciado por Ana García de Fanelli (2009) cuando indica que los concursos en las 
universidades nacionales no se realizan porque son caros, porque hay resistencia a formar parte de los jurados, porque se trata de un procedimiento complejo, porque en las universidades públicas implica acceder a la elección de los gobiernos y porque le quita flexibilidad a los docentes titulares.

Sobre la Universidad de Congreso surge una contraposición en su normativa, ya que el artículo $43^{\circ}$ establece que los docentes pueden ser incorporados a solicitud de directores de carreras y con anuencia del rector; pero tienen una detallada normativa que indica cómo desarrollar el proceso de concursos públicos de antecedentes.

La Universidad Maza menciona el procedimiento de ingreso mediante concurso, sin embargo, que para CONEAU haya una excesiva cantidad de docentes en comparación a la cantidad de alumnos, puede tomarse como un indicador de la falta de planificación para el ingreso a la carrera docente de esta universidad. Esta falta de planificación confirma que el mecanismo de selección, conformado solo por miembros de la universidad, no garantiza transparencia y calidad en la selección e incorporación del personal docente.

En relación a la Universidad del Aconcagua, su normativa no menciona de manera clara el mecanismo de ingreso, ya que indica que a las designaciones efectivas solo se accede por concurso; pero que el ingreso es por medio de una revisión de antecedentes del aspirante.

Si bien la Universidad de Mendoza, no tiene normado el ingreso mediante concurso, sí establece que solo los docentes ordinarios podrán formar parte del "claustro docente" y emitir sufragio en las cuestiones en que sean convocados. Esta universidad es la única que incorpora en su estatuto criterios definidos por CONEAU como informales y subjetivos, tales como "probidad moral y el decoro público". Además, no se hallaron los resultados de la última evaluación a la que fue sometida esta universidad.

La Universidad Champagnat parece ser la que más desafíos tiene por delante para mejorar su normativa y clarificar el proceso de ingreso y desarrollo de la carrera docente.

En síntesis, se puede mencionar que la única universidad en Mendoza que desde lo prescriptivo ha clarificado recientemente el mecanismo de ingreso, es la Universidad de Congreso. Sin embargo, la que parece brindar mejores posibilidades y gratuidad en el perfeccionamiento y actualización de sus docentes, es la Universidad del Aconcagua. Se valora positivamente que la Universidad Maza incorpore en su normativa el ingreso por concurso.

En ninguna de las universidades analizadas es claro el mecanismo de promoción o acceso a las siguientes categorías. Estos aspectos dependen de la toma de decisiones y si los gobiernos no toman un rol activo en relación al cuerpo docente, se pone en peligro el buen funcionamiento de toda la institución.

\section{POSIBLES CAMBIOS O MEJORAS}

Podría tomarse como referencia el Convenio Colectivo de trabajo para los docentes de universidades públicas (2015) con el fin de estandarizar la denominación de las situaciones de 
revista de las universidades privadas en Mendoza. En el mismo sentido, para establecer el régimen de dedicación docente.

Para la permanencia en la carrera docente, se podría implementar evaluaciones periódicas de desempeño, realizadas por pares evaluadores, idealmente externos. Lo que podría materializarse mediante la firma de convenios entre universidades de la región, para la interacción de estas actividades de evaluación docente.

Clarificar los mecanismos de ingreso y de promoción docente, así como hacer públicas las estadísticas relativas al personal docente que ingresa y/o promociona de categoría.

Propender a la publicación y transparencia de gestión de las universidades privadas, permitiría conocer y mejorar las mismas a partir de las investigaciones sobre problemáticas que se detecten con el enfoque de diversos investigadores externos a la institución. 


\section{REFERENCIAS}

Altbach, P. (2009) “It's the Faculty, Stupid! The Centrality of the Academic Profession”. Journal of International Higher Education. Number 55. Center for International Higher Education. Boston College. https://ejournals.bc.edu/index.php/ihe/

Asamblea de asociados de la Universidad Maza. (2014, Diciembre, 9). Estatuto de la Universidad Maza. https://www.umaza.edu.ar/estatuto-de-la-universidad

Asamblea de la Universidad de Mendoza. (1994, Agosto, 31). Reforma del Estatuto de la Universidad de Mendoza. http://www.um.edu.ar/es/sobre-um/estatuto.html\#7

Asamblea General de miembros de la Universidad del Aconcagua. (2003, Noviembre, 18). Resolución 940: Reglamento general de la Universidad del Aconcagua (documentos institucionales). Universidad del Aconcagua. https://www.uda.edu.ar/images/2017/06/08/reglamento_general-fcsa.pdf

Clark, B. (1983). El Sistema de Educación Superior: una Visión Comparativa de la Organización Académica. México D.F.: Universidad Autónoma de México.

Comisión Nacional de evaluación y acreditación Universitaria [CONEAU]. (2017). Creación de instituciones universitarias privadas: La labor de CONEAU 1996 - 2016 (1 ed., documentos institucionales). http://www.bnm.me.gov.ar/giga1/documentos/EL005777.pdf

Comisión Nacional de evaluación y acreditación Universitaria [CONEAU]. (2016-a). Universidad Champagnat: Informe de evaluación externa ( $1^{\circ}$ ed., 60). https://www.coneau.gob.ar/archivos/libros_evaluacion_externa/60UnivChampagnat.pdf

Comisión Nacional de evaluación y acreditación Universitaria [CONEAU]. (2016-b). Evaluación institucional: criterios y procedimientos para la evaluación externa. https://www.coneau.gob.ar/archivos/EvaluacionInstitucional_int_baja.pdf

Comisión Nacional de evaluación y acreditación Universitaria [CONEAU]. (2011). Universidad de Congreso: Informe de evaluación externa ( $1^{\circ}$ ed., 31$)$. https://www.coneau.gob.ar/archivos/libros_evaluacion_externa/EECongreso.pdf

Comisión Nacional de evaluación y acreditación Universitaria [CONEAU]. (2000). Universidad de Mendoza: Informe de evaluación externa (14). https://www.coneau.gob.ar/archivos/publicaciones/evex/mendoza.pdf

Comisión Nacional de evaluación y acreditación Universitaria [CONEAU]. (2017). Universidad del Aconcagua: Informe de evaluación externa (1 ${ }^{\circ}$ ed., 75). http://www.coneau.gob.ar/archivos/libros_evaluacion_externa/75_Aconcagua.pdf 
Comisión Nacional de evaluación y acreditación Universitaria [CONEAU]. (2018). Universidad Juan Agustín Maza: Informe de evaluación externa (1 ${ }^{\mathrm{a}}$ ed., 80). https://www.coneau.gob.ar/archivos/libros_evaluacion_externa/80_Universidad_Maza.pd $\underline{\mathrm{f}}$

Congreso de la Nación Argentina. (1995, Agosto, 10). Ley de educación superior argentina número 24.521. Boletín oficial de la República Argentina. http://www.saij.gob.ar/24521nacional-ley-educacion-superior-lns0004028-1995-07-20/123456789-0abc-defg-g82$\underline{04000 \text { scanyel }}$

Consejo Académico Universitario. (2014). Anexo I de la Resolución 04: Reglamento de la Carrera Docente en la Universidad de Congreso. https://www.ucongreso.edu.ar/wpcontent/uploads/2019/09/ANEXO-I-Res-N\%C2\%BA-4-14-Carrra-docente-ReglamentoConcurso-catedra-2014.pdf

Consejo Académico Universitario. (2001). Estatuto Académico de la Universidad de Congreso.https://www.ucongreso.edu.ar/institucional/estatuto-academico/

Consejo Académico Universitario. (2019). Reglamento General Interno de la Universidad de Congreso. $\quad$ https://www.ucongreso.edu.ar/wp-content/uploads/2015/09/Reglamentogeneral-interno-2019.pdf

Convenio Colectivo para los Docentes de las Instituciones Universitarias Nacionales (2015) Buenos Aires.

Del Bello, A.; Barsky, O. y Giménez, G. (2007). La universidad Privada Argentina. Buenos Aires, Argentina: Libros del Zorzal.

Frondizi, A. (1958). Ley Domingorena $n^{\circ}$ 14557. Buenos Aires, Poder Ejecutivo Nacional. https://www.coneau.gob.ar/archivos/544.pdf

Ganga Contreras, F. (Coord.); Abello Romero, J. y Quiroz Castillo, J. (Eds.). (2014, octubre). Gobernanza universitaria: una mirada histórica y conceptual, pp.11-20. En Gobernanza universitaria: aproximaciones teóricas y empíricas. Santiago, Chile: CEDAC.

García de Fanelli, A. M. (2009). Profesión Académica en la Argentina: Carrera e Incentivos a los docentes en las Universidades Nacionales. Buenos Aires: CEDES

Marquina, M. (2013, Marzo). ¿Hay una Profesión Académica Argentina? Avances y reflexiones sobre un objeto en construcción. Revista Pensamiento Universitario, 15, (15).

Ministerio de Educación. (2013, Diciembre, 3). Resolución 2442: Aprobación del Estatuto Académico de la Universidad Champagnat. Boletín Oficial de la República Argentina. https://www.boletinoficial.gob.ar/detalleAviso/primera/99135/20131210 
Rosenberg, J. (22 de septiembre de 2016). La educación universitaria gratuita cumple 64 años. En comunicación institucional de la Universidad Nacional de San Martín. http://noticias.unsam.edu.ar/2013/11/22/la-educacion-universitaria-gratuita-cumple-54anos/

Sarramona, J., Noguera, J. y Vera, J. (1998) “QQué es Ser Profesional Docente?”. Revista de Teoría de la Educación (10) pp. 95-144.

Universidad de Congreso. (s.f.). [Página institucional]. Nuestra historia: Nosotros. http://www.ucongreso.edu.ar/institucional/\#: :text=La\%20Universidad\%20de\%20Congr eso \%20comenz\%C3\%B3,de\%20Educaci\%C3\%B3n\%20Superior\%20N\%C2\%BA\%2024 $.521 . \&$ text $=$ En $\% 20 \mathrm{el} \% 20 \mathrm{a} \% \mathrm{C} 3 \% \mathrm{~B} 10 \% 202017 \% 201 \mathrm{a} \% 20$ Universidad $\% 20$ super $\% \mathrm{C} 3 \% \mathrm{~B}$ 3\%201os\%205.000\%20alumnos.

Universidad del Aconcagua (agosto del 2018). Universidad del Aconcagua 50 años. Buenos Aires, Argentina: La imprenta ya.

Universidad Maza. (s.f.). [Página institucional]. Nuestra historia. https://www.umaza.edu.ar/institucional 